\title{
INFORME SOBRE MEDIDAS PARA FAVORECER LA PROBIDAD Y EFICIENCIA DE LA GESTIÓN PÚBLICA, ENCARGADO POR S.E. LA PRESIDENTA DE LA REPÚBLICA
}

\author{
Grupo de Trabajo sobre Probidad y Transparencia*
}

\section{INTRODUCCIÓN}

1.

- Orientaciones del informe. El grupo de trabajo conformado por Enrique Barros Bourie, Carlos Carmona Santander, Alejandro Ferreiro Yazigi, Davor Harasic Yaksic, María Olivia Recart Herrera, Salvador Valdés Prieto y José Zalaquett Daher ha recibido de S.E. la Presidenta de la República, Michelle Bachelet Jeria, el encargo de formularle un conjunto de proposiciones conducentes a favorecer la eficiencia, objetividad, responsabilidad pública y calidad profesional de la gestión del Estado. En el plazo asignado, el grupo de trabajo se ha limitado a proponer un diseño institucional básico y algunos lineamientos normativos para procurar esos fines.

El informe omite todo juicio respecto de los graves hechos recientes que han sido discutidos públicamente y que afectan la confianza y el prestigio de la función pública. Se asume a ese respecto que esas conductas están siendo investigadas y serán objeto de pronunciamiento judicial de conformidad con el orden legal vigente. En general, tampoco se proponen cambios en la legislación penal, porque no nos ha parecido correcto hacerlo

* El informe apareció publicado en suplemento del diario La Nación, 26 de noviembre de 2006, pp. 5-12. 
en medio de una disputa pública sobre ilícitos que se habrían cometido. Nuestro objetivo principal ha sido identificar algunos arreglos institucionales básicos que favorezcan los objetivos de largo plazo del Estado de Chile.

El trabajo del grupo ha estado orientado por la idea transmitida por la Presidenta de la República de que las situaciones referidas dan lugar a una inmejorable oportunidad para avanzar en las reformas pendientes y más urgentes, que favorezcan la probidad y transparencia de la gestión pública y la modernización del Estado. En esta tarea, se ha asumido que el diseño institucional debe ser revisado en concreto, a efectos de favorecer que la función pública esté orientada al servicio de la comunidad. Asimismo, se parte de la base que es un bien público importante fortalecer la confianza ciudadana en las personas llamadas al servicio público.

Entendemos que un buen diseño institucional favorece la probidad, la eficiencia y la responsabilidad frente a la sociedad chilena, a la cual se debe la función pública, aunque por sí misma no garantiza resultados. A ese efecto se requiere, además, de voluntad política y de una sociedad civil vigilante.

2. Objeto del informe. En el breve tiempo asignado para su tarea, el grupo de trabajo se ha concentrado en la identificación de los ámbitos prioritarios de acción y en proponer orientaciones fundamentales para una reforma del servicio público. Aunque la atención está puesta principalmente en la gestión de Gobierno, estas proposiciones también favorecen las buenas prácticas en los demás órganos del Estado.

Los temas tratados han sido ordenados en los siguientes grupos:

- $\quad$ Medidas de transparencia activa y pasiva (capítulo II);

- $\quad$ Reformas al sistema de alta dirección pública (capítulo III);

- $\quad$ Financiamiento de campañas y partidos políticos (capítulo IV);

- $\quad$ Reforzamiento de los sistemas de control en el Estado (capítulo V);

- $\quad$ Otras medidas que favorecen la probidad y la transparencia (capítulo

VI)

- Denuncias de buena fe y prohibiciones a ex funcionarios

— Probidad y transparencia en el Parlamento

- Lobby

— Perfeccionamiento de los sistemas de compras y contratación pública

Por lo general, el informe no se refiere a la jerarquía de las normas o directivas que se requieren para instrumentar las proposiciones. Tampoco se pronuncia sobre algunos proyectos de ley en actual tramitación y que versan sobre las materias aquí tratadas. 


\section{PROPOSICIONES EN MATERIA DE \\ TRANSPARENCIA ACTIVA Y PASIVA}

\section{(a) Planteamiento general sobre acceso a la información pública}

3. Importancia. El acceso a información pública es una herramienta crecientemente importante a nivel mundial para mejorar la transparencia y probidad de la gestión pública. Inhibe y disuade malas prácticas, motiva desempeños probos y eficientes y favorece el control social respecto de los actos de la administración. Es, finalmente, parte sustantiva de la libertad de expresión y de la participación ciudadana en cuanto permite a las personas participar en el debate público debidamente informadas.

El principio de la publicidad de la acción estatal ha sido consagrado como una de las bases de la institucionalidad chilena, mediante la reforma constitucional que lo consagró en el nuevo artículo $8^{\circ}$.

\section{(b) Transparencia activa}

4. Principio de iniciativa pública en materia de información. La transparencia activa se expresa en el deber de los órganos del Estado de poner a disposición del público, sin mediar requerimiento expreso, información relevante sobre su gestión. Con ese fin, se propone que los órganos del Estado publiquen permanente o periódicamente, sin necesidad de petición alguna, y en forma accesible al público general, al menos la siguiente información:

- la relativa a su estructura interna, jerarquías, funciones, atribuciones, responsabilidades, presupuesto y otros aspectos patrimoniales y financieros, y cualquier aspecto relevante de los servicios que presten al público;

- $\quad$ la referida a las contrataciones de bienes, servicios y personas y las transferencias que realice a terceros;

- $\quad$ la relativa a los contratistas y a quienes reciban remuneraciones del Estado, con indicación de los RUT personales y de los socios o accionistas principales de los contratistas;

- $\quad$ los objetivos y metas institucionales para cada ejercicio y el reporte acerca del cumplimiento de los correspondientes al ejercicio anterior;

- las normas, regulaciones, actos y resoluciones que tengan efectos sobre terceros.

Corresponderá al organismo autónomo de acceso a la información, señalado en el párrafo 8, recomendar al Presidente de la República los con- 
tenidos adicionales de información, así como definir las modalidades y formatos de publicidad que favorezcan la mejor comprensión de la información pública por parte de los ciudadanos.

\section{(c) Transparencia pasiva o régimen de acceso a la información pública}

5. Transparencia pasiva: insuficiencia de la legislación vigente. La legislación sobre acceso a información pública en Chile, aprobada en 1999, demostró ser ineficaz. Se propone introducir una ley especial que precise y haga efectivo el derecho ciudadano de acceso a la información pública. La experiencia internacional evidencia que esta medida es esencial. El principio rector de la ley debe ser el de máxima apertura y la reserva debe ser sólo excepcional.

6. Excepcionalidad de las restricciones. Las restricciones al acceso a información pública deberán conformarse estrictamente a lo dispuesto en la Constitución y constar en ley de quórum calificado. Esas restricciones deben limitarse a la información:

- $\quad$ que pueda perjudicar la seguridad nacional, la defensa nacional, el orden público, la salud pública nacional, las relaciones internacionales o los intereses económicos del país;

- $\quad$ cuya publicación implique un riesgo para la vida, seguridad, salud o a las legítimas expectativas de privacidad de una persona;

- $\quad$ obtenida de un tercero con carácter de confidencial;

- $\quad$ que pueda ir en desmedro de la aplicación de las leyes, especialmente en lo relativo a la prevención, investigación y prosecución de un crimen;

- $\quad$ comercial y financiera de terceros que merezca protección;

- $\quad$ relativa a deliberaciones de los órganos o funcionarios públicos previas a la adopción de una resolución, medida o política, sin perjuicio de la publicidad de los fundamentos de la resolución, medida o política finalmente adoptada.

7. Principios. La legislación que se propone debiere responder a los siguientes principios:

a) Concepto amplio de información: Se considera relevante toda información que posee un organismo o institución pública, sin importar el 
formato, la fecha en que fue creada, quién la creó o si ha sido clasificada o no.

b) Libertad de información: Toda persona gozará del derecho a información pública, incluyendo el derecho de acceder a información que se encuentre en poder de los órganos del Estado, con las solas limitaciones establecidas en una ley de quórum calificado.

c) Presunción de apertura o principio de transparencia: Toda la información en poder de los órganos del Estado es (o se presume) pública a menos que esté sujeta a las excepciones señaladas.

d) Máxima divulgación: Los órganos del Estado deberán siempre entregar información en los términos más amplios, excluyendo sólo aquella parte de la información sujeta a excepción legal expresa.

e) Facilidad de acceso a la información: La ley contemplará mecanismos y procedimientos para facilitar el acceso a la información, incluyendo la definición de tarifas, las cuales no debieran superar el costo marginal de procesar y entregar la información requerida.

f) No discriminación: Los órganos del Estado deberán entregar información a todas las personas en igualdad de condiciones, sin hacer distinciones arbitrarias; tampoco podrán exigir la expresión de causa o motivo para la solicitud.

g) Prohibición de silencio: Los órganos del Estado siempre deberán responder ante las solicitudes de información, y omitir una respuesta oportuna, sea positiva o negativa, originará sanciones.

h) Fiscalización y revisión independiente de las decisiones sobre entrega de información: Se propone la creación de un órgano autónomo, eventualmente de rango constitucional, que será encargado de promover, difundir y garantizar el derecho de acceso a la información (párrafo siguiente).

Con todo, el mero establecimiento de deberes legales resulta insuficiente. La experiencia internacional indica que es necesario crear una institución autónoma, con atribuciones eficaces y que cuente con los recursos humanos, financieros y logísticos adecuados para cumplir sus funciones. $\mathrm{Al}$ menos 17 países cuentan con un organismo de estas características.

8. Órgano autónomo de acceso a información pública. Se propone la creación de un órgano autónomo de acceso a la información (OAAI) que garantice el acceso a la información pública. Se sugiere que este órgano se ajuste a los siguientes criterios: 
a) Debe contar con la autonomía necesaria para desarrollar su función. Su competencia debe alcanzar a la totalidad de los órganos del Estado, en el entendido que el principio constitucional de publicidad corresponde a una de las Bases de la Institucionalidad. Sería óptimo que tuviera rango constitucional. Se propone que la designación de quien ejerza su jefatura se realice a propuesta presidencial y aprobación por una mayoría de 2/3 partes en el Senado. El directivo superior del OAAI solo debe ser removible por causales estrictas y aprobadas por 2/3 en el Senado.

b) Debe estar dotado de atribuciones resolutivas eficaces, incluyendo la aplicación de sanciones a quienes obstruyan el derecho de acceso a la información pública. Las resoluciones del OAAI que favorezcan la publicidad de la información no serán apelables por la entidad pública requerida; por el contrario, si el OAAI deniega el derecho a la información habrá una acción expedita ante la Corte de Apelaciones respectiva.

c) Tiene que contar con los recursos humanos, financieros y logísticos adecuados para cumplir sus funciones y obligaciones. Su estructura interna deberá garantizar profesionalización, especialización y efectividad. Todos los cargos superiores serán provistos a través del sistema de alta dirección pública.

d) El OAAI deberá cumplir una labor activa permanente en favor de la mayor apertura progresiva de la información. Entre sus atribuciones y obligaciones se encontrarán:

- $\quad$ el monitoreo permanente del cumplimiento de la ley por parte de los órganos del Estado;

- la implementación de una infraestructura que facilite el acceso efectivo a información pública;

- $\quad$ la formulación de proposiciones sobre transparencia activa (supra párrafo 4);

- $\quad$ el diseño de modelos de publicación para facilitar la comprensión y legibilidad de la información;

- la capacitación a los funcionarios públicos respecto al régimen de acceso a la información;

- $\quad$ la realización de campañas de difusión e información al público;

- $\quad$ las relativas a garantizar la debida protección de los datos que deban mantenerse en reserva por causa legal;

- la realización de estadísticas y reportes anuales;

- la formulación de recomendaciones sobre perfeccionamientos legales. 


\section{REFORMAS AL SISTEMA DE ALTA DIRECCIÓN PÚBLICA}

9. Desafíos del sistema de alta dirección pública. El sistema de la alta dirección pública (ADP), que permite la concursabilidad de cargos y define las condiciones bajo las cuales se realizan estos concursos, ha marcado un hito en nuestra institucionalidad. Es necesario, sin embargo, pasar a una segunda fase de desarrollo.

Por ello, hemos considerado prioritarias las siguientes tareas:

a) Invertir en la madurez del sistema; el gobierno debe asumir que el concurso es la manera usual de efectuar todas las designaciones de ejecutivos superiores.

b) Extender el sistema hacia todas las áreas del gobierno, incluyendo programas y servicios donde el responsable defina políticas y sea de designación directa del Presidente de la República o de otra autoridad política del gobierno, con los fines de construir una administración superior profesional, que favorezca la eficiencia, introduzca una práctica generalizada de rendición de cuentas y neutralice el clientelismo.

c) Establecer los correctivos necesarios para que el sistema gane en credibilidad e interés entre profesionales destacados.

10. Procedimientos de concurso. Para favorecer en nivel óptimo la transparencia del proceso de decisión, se debería informar públicamente el puntaje de cada postulante incluido en la terna o quina correspondiente.

Aunque se estima conveniente mantener la privacidad del nombre de los concursantes, porque ello aumenta los incentivos para concursar, en el caso de que un concursante tenga interés en que se certifique que ha formado parte de una terna o quina, el Consejo de la Alta Dirección Pública debe emitir un certificado con esa información.

Un sistema de auditoría extranjera debiera acreditar periódicamente — sobre una base de mejores prácticas comparadas - los procedimientos empleados en el proceso de calificación, selección, apoyo y monitoreo de los altos directivos públicos.

Estas medidas permitirán dar mayor transparencia al sistema y generar credibilidad en el entorno político y profesional. El objetivo perseguido es que el sistema vaya captando los mejores talentos. La auditoría serviría, además, para compararse con las mejores prácticas comparadas y ayudaría al mejoramiento continuo del sistema ADP. 
11. Aplicación de la concursabilidad en servicios incluidos por la ley vigente e incorporación al sistema de nuevos servicios y programas. El sistema de concursabilidad de altas directivas debiera ampliarse sustancialmente para asegurar la eficiencia y objetividad de la función pública.

Para estos efectos se propone distinguir tres tipos de organismos: (i) los que están sujetos por la ley vigente al sistema de ADP; (ii) los que están excluidos del sistema y que debieren estar sujetos en razón de no tener funciones de definir políticas, o bien, porque estas pueden ser reasignadas al ministerio o subsecretaría de la que dependen; y (iii) los que cumplen funciones de definición de políticas, que deben ser dirigidas por un directivo o por un consejo de designación presidencial, pero cuyos altos directivos debieren estar sujetos al sistema de ADP.

$\mathrm{Al}$ respecto proponemos:

a) Servicios incluidos en la ley vigente. Se propone aplicar extensivamente el sistema respecto de los servicios actualmente previstos en el artículo 36 de la ley $N^{0}$ 19.882. Con ese fin se sugiere calendarizar la nominación de cargos superiores en los 99 servicios que están incluidos en la ley y cuyos jefes de servicio aún no han sido concursados, estableciéndose desde luego las fechas en que los funcionarios designados cesan en funciones, sin perjuicio de su derecho a concursar.

b) Nuevos organismos en la ADP. Algunos de los organismos excluidos del sistema de ADP no cumplen funciones de definición de políticas, de modo que debieran ser incorporados al régimen. En otros casos, la función esencial del servicio es de ejecución de políticas, pero también tienen algunas funciones deliberativas, que podrían ser atribuidas al ministerio o subsecretaría que corresponda, de modo que queden íntegramente sometidos al sistema de la ADP. Ejemplos de este grupo de servicios son: Prochile, Dirección General de Relaciones Económicas Internacionales, Casa de Moneda, Comité de Inversiones Extranjeras, Fondo Nacional de Salud, Servicio Nacional de Menores, Servicio Nacional del Adulto Mayor, Dirección de Planeamiento del MOP y ODEPA.

c) Incorporación de nuevos organismos con régimen mixto en la $A D P$. Respecto de organismos donde se opte por no separar la función de fijación de políticas de su ejecución, se propone un régimen mixto, donde el jefe superior del servicio o el consejo que lo dirija sean de libre designación presidencial, pero los cargos ejecutivos estén sujetos al sistema de alta dirección pública. A modo de ejemplo, se propone que queden sujetos a este régimen: CORFO, CONAMA, Dirección del Trabajo, Servicio de Impuestos Internos, Dirección de Presupuesto, Consejo Nacional de Televi- 
sión, Comisión Nacional de Energía, Instituto Nacional de Deportes de Chile, Servicio Nacional de la Mujer, CONADI, Dirección General de Obras Públicas y Consejo de Defensa del Estado.

d) Superintendencias. Las superintendencias deben incorporarse al sistema, ya sea completamente, de modo que el Superintendente y demás directivos sean designados en el marco del sistema; o bien bajo el modelo híbrido o mixto, en cuyo caso el Superintendente es de libre designación presidencial, pero los directivos superiores se seleccionan mediante la ADP.

e) Incorporación de los programas. Parte importante de la gestión pública se desarrolla en la forma de programas especiales que dependen de ministerios u otros órganos políticos. A efectos de mejorar la eficiencia y objetividad, se recomienda incorporar en un plazo breve al sistema de nominaciones por concurso de la alta dirección pública, en primer y segundo nivel, a todos los programas que suponen asignaciones presupuestarias significativas. A modo de ejemplo hemos listado algunos como: Chile Barrio, Chile Califica, Chile Solidario, Programa de Mejoramiento de Barrios, Programa de Mejoramiento Urbano, Conace, Seguridad y Participación Ciudadana, Red de Conectividad del Estado, Fondo Social del Ministerio del Interior, Fortalecimiento de la Gestión Municipal, Protección Integral de la Infancia, Proempleo, Recuperación y Desarrollo Urbano de Valparaíso, Fondo de Innovación de la Competitividad, Programa Nacional de Emprendimiento, Secretaría de Transporte Urbano, Programa de Mujeres Jefas de Hogar, Libros escolares.

f) Directorios de empresas públicas. Sin perjuicio de las demás modificaciones necesarias al gobierno corporativo de las empresas públicas, que no han sido analizadas por el grupo de trabajo, se propone que estas cuenten con al menos un tercio de directores independientes seleccionados de ternas propuestas por el sistema.

g) Municipios. El sistema se debiera expandir progresivamente a los municipios, comenzando por los de mayores presupuestos, dentro de un calendario conocido.

12. Designaciones de funcionarios de segundo nivel. Proponemos designar a los altos directivos ( $1^{\text {er }}$ nivel) antes que a los funcionarios de niveles inferiores. Las ternas o quinas para designaciones en niveles inferiores deben estar siempre precedidas de acuerdos de un comité con mayoría profesional compuesto por (i) el responsable político más directo, (ii) un miembro designado por el Consejo y (iii) el funcionario de primer nivel de designación por concurso del que dependerá el funcionario de segundo nivel. 
No es conveniente que mientras el jefe superior no haya sido designado por concurso, el equipo directivo de segundo nivel pase a estar sujeto al sistema, porque ello conspira contra la formación de equipos homogéneos. El sistema ADP no está completo si el directivo profesional de primer nivel no tiene participación en la designación de su equipo directivo superior.

13. Designaciones de funcionarios de tercer nivel. Si bien la ley del nuevo trato fue un avance, se debe continuar perfeccionando, de modo que en el tercer nivel se incluya la posibilidad de que concursen profesionales externos al sector público. A efectos de mejorar la objetividad del sistema se debe modificar sustancialmente la composición del comité de selección actualmente vigente. Para apoyar el desarrollo de la carrera interna, al funcionario de carrera que pretende ascender se le debiera reconocer una bonificación razonable en el puntaje de calificación.

14. Modificaciones a la estructura de gobierno y remuneraciones del consejo de la alta dirección pública. El Consejo debe constituirse en directorio con facultades verticales al interior de la organización. No es funcional que el Consejo carezca de potestades organizacionales en las áreas de su competencia.

A efectos de facilitar la relación del Consejo con el Gobierno, se propone que el quinto miembro del Consejo sea el Ministro o Subsecretario de Hacienda u otra persona de designación del Presidente de la República y que el Director Ejecutivo del Servicio Civil sea secretario técnico del Consejo. El Presidente del Consejo debiera ser designado por sus miembros.

En circunstancias que el Consejo ampliará sus funciones resulta necesario revisar el régimen de remuneraciones de sus miembros, asumiendo que ya tienen una dedicación superior a la prevista originalmente.

15. Direcciones de alta dirección pública y de desarrollo de personas. Del consejo de alta dirección pública debieren depender las direcciones de alta dirección pública y de desarrollo de personas. Se propone que los directores y demás personal superior sean designados por el Consejo, previo concurso llamado de acuerdo con las reglas de alta dirección pública.

16. Remuneraciones de los altos directivos públicos. Existen razones de interés general para que quienes ejerzan la alta dirección pública obtengan remuneraciones que alienten a concursar a profesionales de excepción. Es mucho lo que pierde el país cuando por razones económicas se reduce la posibilidad de reclutar y mantener en el servicio público a los profesionales 
que pueden dirigir organismos encargados de tareas complejas y cuantiosos recursos públicos con la excelencia requerida.

El concepto rector para estos efectos es que las distancias de sueldos con el sector privado no pueden superar el valor de satisfacción marginal que el interesado asigna a trabajar en el sector público. Ello equivale a reconocer que esa satisfacción suele ser menor a la de quienes ejercen cargos políticos de primer plano, de modo que nada debiera obstar, en principio, para que en ciertos casos los ejecutivos superiores obtengan rentas mayores que las máximas autoridades políticas.

Hay cargos en que se produce una capitalización profesional, pero en otros el costo de oportunidad es muy elevado ${ }^{1}$. Por ello, es recomendable que el rango de las asignaciones de alta dirección pública sea ampliado, de modo de llegar, como límite, por ejemplo, al nivel de un consejero del Banco Central. El Consejo deberá formular la recomendación salarial específica para cada cargo dentro del rango definido.

A efectos de disminuir discrepancias entre el Consejo y la Dirección de Presupuesto, es conveniente que se encarguen estudios de remuneraciones para cargos homologables y que en conjunto se definan criterios para la determinación en concreto de las asignaciones. La Dirección de Presupuesto deberá pronunciarse dentro de 30 días respecto de las asignaciones propuestas por el Consejo.

17. Asesores. Debe reservarse el derecho de los ministerios a tener asesores de libre designación, de alta calificación profesional. Los honorarios de los asesores debieran ser definidos dentro de rangos y por montos globales predefinidos.

La nómina, curricula y honorarios de los asesores deben ser públicos.

\section{EL FINANCIAMIENTO DE CAMPAÑAS Y PARTIDOS POLÍTICOS}

18. Reforzar la transparencia en la relación entre el dinero y la política. La democracia requiere una relación transparente entre la política y la influencia del dinero, sea de origen privado o estatal. La gravedad de los

${ }^{1}$ Por ejemplo, en el caso de los directores de hospitales, la prohibición de dedicarse al menos parcialmente a la práctica clínica significa un riesgo de desactualización profesional muy significativo que termina disuadiendo la participación de médicos en estos cargos. Se propone, al efecto, facultar al Consejo para ajustar la exigencia de dedicación exclusiva, de modo que pueda, por ejemplo, permitir que los médicos puedan destinar la misma jornada a la práctica clínica que otras normas administrativas conceden para el ejercicio docente a funcionarios de dedicación exclusiva. 
hechos recientes, en materia de control y contabilidad de las candidaturas, y su repercusión pública, demuestran la necesidad de ampliar y afinar los ilícitos por violaciones a la ley electoral, así como aumentar el control y la fiscalización.

Los integrantes del grupo de trabajo no necesariamente coinciden acerca del régimen óptimo de financiamiento electoral, en materias como los niveles de gasto autorizado, la validación de los aportes de personas jurídicas y la existencia de donaciones reservadas. Sin embargo, el grupo de trabajo entiende su trabajo circunscrito a velar porque la legislación recientemente dictada se cumpla efectivamente en letra y espíritu, y a ello apuntan las siguientes recomendaciones.

19. Ampliar y afinar los ilícitos y sanciones por violaciones a la ley electoral. Existe un extendido consenso respecto de la imprecisión de los ilícitos, así como de la debilidad de las sanciones legales actualmente vigentes para prevenir ilícitos relativos al financiamiento electoral. Sin perjuicio de la necesidad de efectuar un análisis más acabado sobre el particular, nos parece necesario proponer reformas que apunten a los siguientes objetivos:

a) Se requiere atribuir a los candidatos responsabilidades patrimoniales y políticas por los hechos cometidos por sus administradores electorales.

b) Se considera necesario avanzar a la tipificación de delitos por infracciones a las normas vigentes sobre financiamiento, gasto y rendición de cuentas.

c) En caso de que un tribunal dictamine graves responsabilidades personales de algún candidato en las infracciones a las normas sobre gasto electoral, se propone como sanción la pérdida del cargo, así como la inhabilidad para ser funcionario público o para ser candidato a cargos de elección popular durante diez años.

d) Se propone, asimismo, establecer sanciones que afecten parte del financiamiento público futuro a los partidos que incurran en irregularidades y que se sancione con multas en los rangos autorizados a la Superintendencia de Valores y Seguros a los sujetos privados que incurran en donaciones anónimas o en otros ilícitos de financiamiento de campañas o partidos.

e) Se propone ampliar el plazo de prescripción para las faltas a la ley 19.884 desde uno a dos años (artículos 33, 55 y 57).

f) Se sugiere extender el plazo para la auditoría externa de la contabilidad de término de campaña a 45 días y ampliar plazo de la prórroga a otros 45 días (artículo 42 ley $\mathrm{N}^{\circ} 19.884$ ). 


\section{Crear una dirección de fiscalización electoral robusta y libre de} conflictos de interés. La eficacia de los actos eleccionarios para resolver la rivalidad política requiere mantener la confianza de los principales competidores en la imparcialidad de la entidad organizadora y de control. La desconfianza en ese plano podría alentar impugnaciones de resultados y boicots, como se ha visto en otros países.

La confianza requerida respecto de quien ejerza las funciones de supervisión de los actos eleccionarios no puede, sin embargo, conseguirse a cambio de limitar su capacidad de fiscalización de gastos e ingresos. Ello obliga a buscar el arreglo institucional que permita contar, por un lado, con una capacidad legítima y robusta de fiscalización en un área de suyo compleja y conflictiva y, por el otro, con la autonomía institucional que favorezca su imparcialidad real y percibida. Al respecto se propone:

a) Modernizar la institucionalidad de la autoridad electoral. Ello incluye crear, en forma separada una Dirección de Servicio Electoral encargada de las funciones de registro y organización de elecciones, y una Dirección de Fiscalización Electoral responsable de la fiscalización, auditoría y control, de un modo que las libere de conflictos de interés y les garantice su autonomía y objetividad.

b) La Dirección de Servicio Electoral estará encargada de las funciones de registro electoral y del proceso electoral; asimismo tendrá la función permanente de proponer modificaciones que simplifiquen y modernicen los procedimientos de registro y los procesos eleccionarios.

c) La Dirección de Fiscalización Electoral tendrá facultades normativas; podrá instruir, por ejemplo, la adopción de medidas de control interno para campañas y partidos. Su personal directivo será seleccionado conforme al sistema de la alta dirección pública. Estará facultada y contará con el financiamiento necesario para contratar empresas de auditoría externa inscritas en la SVS.

d) A la cabeza de las reparticiones que desempeñan las tareas de registro y organización electoral, por un lado, y de fiscalización y control, por el otro, debiera instalarse un Consejo Electoral integrado por miembros designados por el Presidente con acuerdo del Senado e inamovibles por el período de su designación.

21. Aumentar el control y la fiscalización del gasto electoral. En esta materia se propone:

a) Obligar a cada candidatura a pagar todos sus gastos con una cuenta bancaria única y recibir todos sus ingresos en esa misma cuen- 
ta; no habrá secreto bancario respecto de la Dirección de Fiscalización Electoral;

b) Que los gastos deberán pagarse con cheque nominativo y cruzado (o con transferencia electrónica), asegurando la existencia de un registro de beneficiarios de los gastos de campaña;

c) Crear un registro previo de proveedores, pero sólo para las candidaturas presidenciales y parlamentarias y para los partidos políticos, y permitiendo que el pago al proveedor se haga de inmediato y directamente por la candidatura; de este modo sería posible a la Dirección de Fiscalización Electoral investigar los antecedentes de los proveedores apenas soliciten inscribirse;

d) Exigir que las candidaturas presidenciales, parlamentarias y de alcaldes en comunas con más de 10 mil electores, y los partidos políticos, entreguen sus rendiciones de ingreso y gasto en forma electrónica a la Dirección de Fiscalización Electoral;

e) Que la Dirección de Fiscalización Electoral mantenga publicado en Internet el listado de personas jurídicas privadas que tienen prohibido donar a candidaturas y partidos, por estar postulando a licitaciones públicas, o por otras razones. La Dirección del Servicio Electoral deberá consultar y comparar ese listado con la identidad de quienes efectúen donaciones privadas.

\section{Proposiciones para restringir donaciones anónimas y crear nuevo} mecanismo para favorecer aportes reservados de personas de bajo monto.

a) Las donaciones anónimas (Ley No 19.884, artículo 17) constituyen una fuente de fondos de campaña que facilita la intervención electoral. Aunque también pueden originarse en una legítima simpatía política, nada impide que ellas sean producto de presiones indebidas de terceros contra el donante o comprometan la independencia del candidato que las recibe. Además, como las recibe la candidatura en privado, no hay verificación de que cada una sea inferior a 20 UF. Se propone prohibir las donaciones anónimas para las candidaturas presidenciales, parlamentarias y de alcalde en comunas con más de 10 mil inscritos en el registro electoral. Para las demás campañas, de menor tamaño, se propone reducir el máximo permitido hasta ahora para estas donaciones.

b) Para canalizar las donaciones pequeñas legítimas, se propone crear un nuevo sistema de donaciones electrónicas para personas naturales, que esté protegido de la intervención electoral y que sea de fácil acceso para la ciudadanía. Se propone que este medio electrónico permita transferir 
dinero al SERVEL e indicar el beneficiario en un solo acto, y que proteja al donante de presiones indebidas de terceros por medio de una opción para revertir el aporte en forma reservada.

c) Se estima conveniente otorgar apoyo fiscal a las donaciones que usen este nuevo sistema de donaciones electrónicas de personas naturales. Se propone que el fisco incremente con fondos públicos en un porcentaje las donaciones de personas naturales que sumen menos de 20 UF por período de campaña y que usen los medios electrónicos aprobados.

Este apoyo se justifica para cubrir los costos administrativos de promover las donaciones pequeñas y para promover la participación política de personas naturales. El porcentaje no debiera ser superior a la tasa del impuesto de primera categoría vigente a la fecha de la elección (17\%).

\section{Proposiciones para asegurar transparencia efectiva y control de los aportes privados.}

a) Los aportes privados de carácter público que son superiores a 20 UF son recibidos, bajo la ley vigente, por los propios partidos y candidaturas. Esto impide a la ciudadanía verificar la identidad del donante consignado. Como correctivo se propone que estos aportes sean pagados a la Dirección de Servicio Electoral (Servel), quien verificaría la identidad del donante y transferiría el dinero a los beneficiarios, incluyéndolo en la suma que transfiere semanalmente por concepto de donaciones privadas. Se propone también que el Servel publique en internet toda la información de las donaciones privadas de carácter público que reciba y transfiera.

b) La evidencia disponible muestra que en no pocas ocasiones el carácter reservado de las donaciones no se puede garantizar. Con el fin de corregir esta situación se propone introducir en la ley los correctivos técnicos necesarios ${ }^{2}$.

${ }^{2}$ El mecanismo vigente para donaciones importantes (superiores a 20 UF) no logra reserva cuando el número acumulado de destinaciones al candidato en toda la campaña es 1 ó 2 . Se propone que la ley fije el umbral de saldo pendiente que redunda en un traspaso total en la siguiente distribución semanal (ese umbral fue \$1.000 en 2005), en una cifra significativa, por ejemplo la mayor entre 2 UTM y 10\% de la destinación. La reserva se recuperaría traspasando el saldo al partido del candidato, al término de la campaña.

En el caso de candidatos independientes, se propone traspasar el saldo pendiente a un fondo común de todos los independientes. Al término de la campaña, este fondo común sería distribuido entre todos los independientes a prorrata de las donaciones reservadas totales destinadas originalmente a cada uno. 


\section{Formalización, control y transparencia de las elecciones prima-} rias. Las elecciones primarias han pasado a tener una importancia fundamental en un sistema político conformado, principalmente, por grandes bloques electorales. Excluir las elecciones primarias de las normas sobre financiamiento electoral no resulta consistente con la función que pueden tener la manifestación de la voluntad ciudadana. Por ello, parece necesario avanzar hacia la regulación legal de las primarias, aplicándoles las normas que garanticen el cumplimiento de los objetivos de transparencia, limitación del gasto y del período de campaña y equidad en el acceso al financiamiento propios de las elecciones generales. En anexo a este informe, se desarrolla una propuesta básica de regulación.

\section{Regulación de actividades que puedan suponer intervención elec-} toral indebida. Una mejor regulación y fiscalización del régimen de financiamiento de las campañas persigue transparentar y canalizar adecuadamente la relación entre el dinero y la política, con el fin de velar, tanto por la expresión libre e informada de los ciudadanos, como por una equitativa posibilidad de participación electoral de los distintos candidatos y partidos. Esta misma finalidad debe buscarse por la vía de prevenir la intervención electoral indebida de parte de quienes detentan el poder del Estado y lo utilizan para fines electorales distintos del bien común.

En tal sentido, parece necesario revisar la legislación y fiscalización de modo de impedir que el poder del Estado se use en beneficio de las campañas oficialistas. Al respecto, y sin perjuicio de otras medidas, se propone:

a) Restringir el uso de las urgencias legislativas en épocas de campañas electorales.

b) Prohibir los avisos publicitarios de las políticas de gobierno, salvo en lo concerniente a campañas impostergables de utilidad pública, durante la vigencia del período de campañas electorales.

c) Prohibir realizar colectas con fines de campaña al interior de las reparticiones públicas con el patrocinio directo o indirecto de las jefaturas.

\section{REFORZAMIENTO DE LOS SISTEMAS DE CONTROL EN EL ESTADO}

26. Necesidad de redefinir las funciones de control. Los sistemas de control de la actividad del Estado son parte esencial de un servicio público de buen nivel. Se comparte el diagnóstico de que en la materia el país no ha 
tenido un desarrollo consistente con los cambios, complejidad y ampliación de las funciones del Estado.

El control comprende tres aspectos fundamentales: (i) legalidad, (ii) auditoría contable y (iii) evaluación de eficiencia y cumplimiento de metas. Estas tres funciones deben ser atribuidas en su propio mérito.

Los sujetos de control debieren extenderse a las empresas del Estado (salvo que estén sujetas al estatuto de la sociedades anónimas abiertas), a las municipalidades y a las organizaciones no gubernamentales que reciben aportes estatales.

\section{Estructura y funciones de la Contraloría General de la República.} La Contraloría requiere urgentes reformas a su concepción funcional y organizacional, que en esencia tiene ya 80 años.

Algunas de sus funciones actuales deben ser conservadas, sin perjuicio de la necesaria revisión de su organización y procedimientos de control. Otras, como se verá, debieran ser ejecutadas por otros órganos.

Es esencial que la Contraloría focalice su actividad en las tareas que le son más propias e insustituibles: la auditoría contable y el control de legalidad de los actos de la administración. Para el cumplimiento óptimo de esas tareas es necesario modernizarla. La urgencia y amplio alcance de las reformas institucionales que debiera abordar la Contraloría sugieren contar con la asistencia de los organismos contralores de mayor prestigio mundial, que hayan abordado reformas similares en los últimos años.

28. Control jurídico o de legalidad. El trámite de toma de razón debe estar limitado a las materias que expresamente se designen y con criterios restrictivos. La extensión que hoy alcanza la toma de razón, según criterios definidos por la propia Contraloría, genera dudas sobre la posibilidad de efectuar un análisis más allá de lo formal, acarrea retrasos injustificados en la ejecución y supone una distracción de recursos de dudosa eficiencia. La regla general, más aún si se avanza decididamente hacia la publicidad proactiva de los actos de la administración, debiere ser el control ex post, bajo las formas de auditoría legal y de dictámenes que obliguen a la administración, a menos que se obtenga un pronunciamiento en contrario de los tribunales.

La Contraloría debe ser desprovista de sus funciones de tribunal de cuentas, porque su tarea es de control externo, de modo que si encuentra irregularidades debiere formular cargos; siguiendo los principios del debido proceso, el órgano que tiene esta última tarea no debiere asumir la función jurisdiccional. Ello supone crear un tribunal de cuantías especializado, que no requeriría de una gran dotación. 
29. Contabilidad y auditoría externa. Estas funciones no debieren ser ejecutadas por el mismo órgano en atención a su diferencia esencial, y a los eventuales conflictos de interés que pueden suponer. Es sintomático que el llamado Informe de Gestión Financiera del Estado actualmente no sea auditado. Por eso, deben separarse funcional y orgánicamente:

- $\quad$ la contabilidad general de la Nación, que podría estar a cargo de un órgano independiente, que puede estructurarse de conformidad a los criterios de alta dirección pública; y

- $\quad$ la auditoría externa del gobierno, que debiere estar a cargo de Contraloría.

30. Control y evaluación de eficiencia y resultados. En materia de control de gestión y evaluación de impacto de las políticas y programas públicos, parece conveniente contar con un sistema autónomo de evaluación que garantice la independencia, calidad y publicidad de sus resultados, y que complemente los actuales sistemas internos de evaluación a cargo de la Dirección de Presupuestos. Hay experiencia internacional que sugiere que tal instancia se vincule al Congreso Nacional.

31. Auditoría interna de gobierno. Es razonable y necesario que el gobierno tenga un sistema interno de monitoreo de la ejecución de políticas públicas. Se propone establecer un órgano que asista al Presidente de la República en los aspectos políticos de cumplimiento de las metas y en la verificación de la eficiencia de la gestión y, en especial, a la prevención de riesgos de distracciones de fondos y otras irregularidades. Esta tarea la desempeña actualmente el Consejo de Auditoría Interna General de Gobierno. Al respecto se propone que:

- $\quad$ el director de este Consejo sea designado libremente por el Presidente de la República;

- $\quad$ sus ejecutivos de primer y segundo nivel están sujetos a las normas sobre alta dirección pública;

- $\quad$ se establezcan mecanismos institucionales que favorezcan la fiscalización continua, incluyendo especialmente los ámbitos de asignación directa de recursos (materia que también debe ser objeto de publicidad y del control externo referido en el párrafo anterior y de la auditoría de la Contraloría). 


\section{OTRAS PROPUESTAS QUE FAVORECEN LA PROBIDAD Y LA TRANSPARENCIA}

\section{(a) Denuncias de buena fe y prohibiciones a ex funcionarios}

32. Un sistema efectivo de protección al denunciante de buena fe. Elevar la probabilidad de ser denunciado reduce la disposición a incurrir en un delito o ilícito administrativo. Ello requiere proteger adecuadamente a quienes los denuncien de buena fe y por los canales regulares.

Quienes están en mejor posición de conocer de actos de corrupción que involucren a funcionarios son los particulares afectados, los co-partícipes en el ilícito o en los planes para cometerlo y los funcionarios públicos que conozcan de ellos en razón de sus funciones. Todos ellos, sin embargo, pueden inhibirse de denunciar por temor a represalias. Por otro lado, las normas de tratados anticorrupción de que Chile es parte estipulan la obligación de proveer protección a los denunciantes. Si bien las normas penales y procesales vigentes reconocen como atenuante la denuncia útil para sancionar un delito efectuado por quien tuviera participación punible en su comisión y permiten una adecuada protección a testigos, este beneficio no alcanza a quienes no tienen responsabilidad penal y, por ende, solo resuelve parcialmente el problema ${ }^{3}$.

En consecuencia, resulta necesario establecer medidas de protección, para las personas particulares o funcionarios públicos que de buena fe y del modo que la ley señale, denuncien que se cometió, o existe alta probabilidad de que vayan a cometerse, actos que constituyan un delito u otro incumplimiento de un deber legal relativo a la probidad pública, o bien denuncien que se ocultó o pretende ocultarse información relacionada con tales actos.

Se propone que la ley regule:

a) Quiénes pueden impetrar protección, cómo y ante quién deben formular la denuncia para que en principio sean aplicables las medidas de protección.

b) Las medidas específicas de protección que podrán arbitrarse a favor del denunciante.

c) La autoridad que puede disponer las medidas de protección y verificar su cumplimiento, así como los procedimientos del caso.

${ }^{3}$ El artículo $11 \mathrm{~N}^{\circ} \mathrm{s} 8$ y 9 del Código Penal considerará como atenuantes de responsabilidad penal las denuncias útiles formuladas por quienes hayan tenido participación punible. Por su parte, el artículo 308 del Código Procesal Penal establece normas aplicables a la protección de los testigos. 
d) Las situaciones de riesgo o represalia que, de existir temor fundado que puedan ocurrir en contra del denunciante, justificarían la aplicación de una o más de las medidas de protección.

e) Las sanciones que proceden frente a denuncias frívolas o de mala fe.

33. Mejoramiento de las normas actuales que establecen prohibiciones a ex funcionarios públicos. En Chile existe una regulación parcial e imperfecta de las actividades laborales que un ex funcionario público - especialmente regulador o fiscalizador - puede desempeñar bajo dependencia de quienes antes fueron sus supervisados. La norma actual, contenida en el artículo 56 de la Ley de Bases de la Administración del Estado, establece una prohibición por seis meses, sin indemnización, y cuya infracción carece de sanción efectiva, pues sería cometida por quien ya no es funcionario público y, en consecuencia, escapa al poder disciplinario de la administración.

La norma vigente es tímida e incompleta a la luz de lo que se observa en otros países. Es tímida, porque establece una prohibición o cuarentena laboral sólo por seis meses y sin sanción efectiva. Es incompleta, porque a diferencia de lo que se observa en la mayoría de los países de la OCDE y, en el caso de los organismos reguladores ha pasado a ser un cierto estándar internacional, no se contempla una indemnización compensatoria a quien, al dejar su cargo público, no podrá desempeñarse en las áreas profesionales en las que es más calificado y competente.

Con los fines señalados, se propone legislar con los siguientes fines:

a) Se prohíba a los directivos de entidades fiscalizadoras desempeñarse en el área privada previamente regulada durante el año siguiente a la cesación en su cargo.

b) Se establezca una compensación monetaria durante el tiempo de vigencia de la prohibición o, alternativamente, se establezca una asignación especial que anticipe el pago de la indemnización, de modo de incorporarla a la remuneración mensual.

c) Se identifiquen otros altos funcionarios que tomen decisiones de políticas públicas que directamente afecten a sectores determinados de la actividad empresarial, a quienes corresponda extender la inhabilidad y, eventualmente, la compensación señalada.

d) Que la regulación del post-empleo público debe alcanzar a la prohibición, por el tiempo que señale la ley, que no deberá ser menor a dos años, para que ex altos funcionarios públicos puedan desempeñarse como lobbystas. 


\section{(b) Probidad y transparencia parlamentaria}

34. Comisiones de Ética o buenas prácticas parlamentarias. Las comisiones de ética del parlamento están previstas, pero su funcionamiento es imperfecto. Algunos casos de irregularidades cometidas por parlamentarios no han contado con pronunciamientos oportunos y suficientemente explícitos de las instancias de autorregulación respectivas.

La integración de las comisiones, en las que los parlamentarios pueden ser juez y parte a la vez, conspira contra el debido funcionamiento de estos comités. Al respecto se sugiere que las cámaras del Congreso Nacional revisen el funcionamiento de sus comités de ética de modo de:

- $\quad$ evaluar la incorporación de personas de reconocido prestigio, incluyendo ex parlamentarios, pero ajenos a la Cámara correspondiente, de modo que quien emita los pronunciamientos o dictámenes tenga la debida independencia respecto de quienes son afectados por tales pronunciamientos; una composición independiente corresponde al estándar mundial en instancias de autorregulación protegidas de la defensa corporativa;

- $\quad$ actualizar los códigos de buenas prácticas parlamentarias de conformidad a los mejores estándares internacionales disponibles;

- Hacer públicos los contenidos de esos códigos y la actividad de los comités.

35. Corrección de vacíos en materias de conflictos de interés. Se estima conveniente reforzar las normas que impiden a los parlamentarios desarrollar actividades privadas simultáneas que puedan suponer conflictos de interés.

En especial, se recomienda especificar ejemplarmente y establecer sanciones a la infracción de la norma que prohíbe votar o promover asuntos en los que un parlamentario tenga interés, actualmente contenida en el artículo $5^{\circ} \mathrm{B}$ de la Ley Orgánica Constitucional del Congreso Nacional.

36. Fuero parlamentario. El Tribunal Constitucional ha declarado en varias oportunidades que la actual regulación del desafuero de parlamentarios por delitos de acción privada, es inconstitucional, pues se permite decretarlo con los antecedentes que se acompaña en la querella, lo que viola en su opinión el principio del racional y justo procedimiento.

Es necesario establecer una regulación que garantice dicho racional y justo procedimiento, ya que la actual situación hace imposible que un 
parlamentario responda penalmente, por ejemplo, por injurias y calumnias. Ello transforma la inviolabilidad parlamentaria, que se garantiza sólo para sesiones de sala y comisión, en una inmunidad general injustificada.

\section{(c) Lobby}

37. Acelerar la tramitación del proyecto de ley que regula el lobby y perfeccionar su contenido. En una democracia todos los ciudadanos tienen derecho a representar sus propios intereses individuales o colectivos ante la autoridad política y tienen derecho a organizarse en torno a esos mismos intereses. El lobby consiste en realizar gestiones de representación de intereses ante autoridades públicas en forma directa y privada. El carácter privado y directo de esta actividad requiere de una norma que facilite el conocimiento público de sus acciones y obligue a quienes las realizan a cumplir con ciertos requisitos de procedimiento que garanticen igualdad de oportunidades de representación. Lo que busca proteger una ley de lobby es la equidad en el acceso a la posibilidad de ejercer influencia, mediante la transparencia de las gestiones que realizan entidades que tienen un poder para hacer valer sus intereses significativamente mayor al de otros.

Una ley de regulación del lobby no implica limitación alguna al respecto del derecho de petición, en la medida que sólo impone requisitos de procedimiento que garantizan transparencia, sin establecer barreras al derecho de petición. Una ley de lobby eficaz debe contemplar los siguientes criterios:

a) Una definición precisa de lobby. Debe definirse como cualquier acción que consista en tomar contacto directo y privado (reunión, mail, teléfono) con una autoridad con el fin de promover un interés particular de cualquier tipo, económico o de otra naturaleza. Deben definirse claramente las autoridades y representantes frente a quienes se considerará que se realiza lobby cuando se los contacta para promover un interés particular. Ellas deberán definirse bajo el criterio de la capacidad de tomar decisiones en forma autónoma en su ámbito de competencia o de tener influencia en quien puede tomarla (asesores directos y de exclusiva confianza).

b) Una buena definición de lobbysta: Debe definirse como aquella persona que realiza una acción descrita como lobby. Puede ser quien lo realiza en forma exclusiva para un tercero (oficina de lobby) o quien lo realiza dentro de una organización como parte de sus funciones frecuentes o habituales (cualquier cargo dentro de una empresa que tenga por función esta actividad, representante de entidad gremial, representante de sindicato, 
ONG, fundación, centro de estudio, colegio profesional o cualquier organización que promueva un interés cualquiera sea su naturaleza u origen). Pero en ambos casos se debe exigir además la existencia de un grado significativo de profesionalización y de remuneración, para evitar que se califique de lobbysta a quien ejerce su derecho a representar sus propios intereses individuales o colectivos ante la autoridad política.

c) Exigencia de contar con un registro público donde se inscriban, al menos, quienes hacen o pretenden hacer lobby como actividad profesional. Dicho registro debe ser público, fiscalizable, exhaustivo y actualizado periódicamente.

d) Exigencia de contar con reportes regulares de la actividad de los lobbystas para proveer información al público sobre a quienes han abordado y por qué motivo. Esta información debe ser completa, veraz, fiscalizable y pública.

e) Establecimiento de incompatibilidades para quienes no están autorizados para desarrollar esta actividad, especialmente a quienes abandonan cargos públicos y pasan al sector privado o quienes forman parte de las directivas de los partidos políticos.

f) Exigencias para las autoridades públicas de hacer públicos los contactos realizados por los lobbystas; la regla debiera extenderse a cualquier autoridad administrativa, política o judicial que recibe privadamente comunicaciones de alguna de las partes interesadas en una decisión pendiente ante esa misma autoridad.

g) Prohibiciones a los lobbystas para involucrarse en el financiamiento de campañas electorales.

h) Sanciones deben ser suficientemente fuertes para desincentivar el ejercicio solapado de influencias.

\section{(d) Perfeccionamiento de los mecanismos de compras y contratación pública}

38. Planteamiento. El Sistema de ChileCompra ha transparentado los llamados a licitación para adquirir bienes y servicios por parte del Estado, entregando información detallada al público y a postores interesados. Las propuestas a continuación tienen por objetivo profundizar la operación y alcance de este Sistema.

39. Extender la transparencia de ChileCompra a las licitaciones de todos los contratos administrativos en los cuales ella sea factible. Transparentar los llamados a licitación que aún se encuentran excluidos permitirá 
uniformar los procedimientos de licitación, fortalecer el control social, aumentar la competencia y elevar la certeza jurídica.

Se propone incluir la publicación en el portal de ChileCompra de todos los llamados a licitación para ejecución y concesión de obras, de los llamados a licitación de contratos de concesión de bienes públicos, y los llamados a licitación de servicios de apoyo municipal y del gobierno central. Alternativamente, se propone imponer a estas operaciones estándares de transparencia que sean comparables a los logrados por ChileCompra.

40. Acreditar y elevar exigencias a responsables de compras y contrataciones. Se propone exigir que todos quienes cumplan funciones de gestión de compras públicas cumplan requisitos de certificación de habilidades y antecedentes, sea que lo hagan a través de ChileCompra o de otros mecanismos.

Se propone obligar a cada jefe de servicio, programa o institución del Estado, a dictar una resolución que deberá ser publicada en su sitio de que individualice al funcionario del estamento directivo de la institución que es responsable del cumplimiento de las normas sobre adquisiciones de bienes y servicios y, si los hay, a los demás funcionarios que participan en forma permanente en la función de compras. Estas personas deberían además estar individualizadas en el portal de ChileCompra y cumplir con los siguientes requisitos:

- declaración de intereses y patrimonial (algunos no están cubiertos por la exigencia vigente porque sus puestos tienen jeraquía inferior al tercer nivel);

- $\quad$ antecedentes comerciales, que no podrán exhibir impagos mayores;

- $\quad$ certificación de habilidades mediante una prueba anual que evaluará las normas técnicas, reglas de buenas prácticas y de conocimientos y habilidades en materia de abastecimiento, aplicación de normativa, ética, uso del sistema ChileCompra, entre otros contenidos.

En algunos municipios pequeños se hace difícil hacer cumplir las normas sobre inhabilidades para los funcionarios de compras. La estrategia propuesta es sustituir esas normas por obligaciones de transparencia. Se propone autorizar a cada funcionario de un municipio con menos de diez mil habitantes, cuya tarea habitual incluya la gestión de compras, a solicitar a ChileCompra una exención de una o más de las inhabilidades o incompatibilidades que la ley impone para ejercer la función. Autorizar a ChileCompra a conceder esa exención, que no durará más de dos años, siempre que el 
funcionario declare expresamente y por escrito las causales de inhabilidad o incompatibilidad por las cuales solicita excepción. Estas declaraciones serán parte del documento con que se publicarán en el portal de ChileCompra las compras que gestione este municipio, y también se entregará en copia escrita de dicha declaración a los interesados que retiren bases en forma física.

41. Propuestas concretas de mejoramiento constante de los procedimientos de compras públicas

a) Obligar a los organismos públicos adscritos al sistema ChileCompra, incluyendo a los programas, a elaborar y publicar una Guía de Procedimientos que cada uno seguirá obligatoriamente en sus procesos de compras. La página que publicite esta guía debería incluir un sistema de recepción de críticas y comentarios de parte de usuarios y potenciales postores. Las críticas y comentarios deberán ser publicados en la misma página, seguidos por la respectiva respuesta del organismo.

b) Fortalecer las redes y contactos entre jefes de adquisiciones y de compras en el sector público.

c) Invertir en capacitar a los funcionarios involucrados en compras públicas, en forma coordinada con la Dirección de Desarrollo de Personas de la Dirección Nacional del Servicio Civil.

d) Estudiar y evaluar la factibilidad de conferir el carácter de falta grave a la probidad administrativa el incumplimiento de las normas sobre contratación administrativa, contempladas en la ley y en el reglamento. Ese proyecto deberá recoger la heterogeneidad de procesos de compras y responder a ella de manera flexible.

e) Realizar auditorías del proceso de compras públicas chileno, usando referencias internacionales, incluyendo las prácticas desarrolladas por el sector privado de los países avanzados. También se propone difundir el resultado de estas auditorías.

\author{
Enrique Barros Bourie \\ María Olivia Recart Herrera \\ José Zalaquett Daher
}

Davor Harasic Yaksic

Salvador Valdés Prieto

Alejandro Ferreiro Yazigi

Coordinador

Carlos Carmona Santander

Secretario 


\begin{abstract}
ANEXo I
PROPOSICIONES PARA FORMALIZAR, CONTROLAR Y TRANSPARENTAR LAS ELECCIONES PRIMARIAS PARA CANDIDATURAS PRESIDENCIALES, SENATORIALES Y DE DIPUTADOS
\end{abstract}

- $\quad$ Los objetivos son dos: desalentar el clientelismo en las elecciones internas y aplicar a las campañas internas normas de control y transparencia del gasto electoral.

- $\quad$ Para desalentar el clientelismo en las elecciones internas, se propone recoger la experiencia internacional según la cual el clientelismo se desalienta progresivamente, y es sustituido por publicidad de propuestas, a medida que aumenta el número de participantes en la elección.

Sobre la base de este antecedente, se propone ofrecer un paquete de beneficios a los partidos que acepten el costo de adoptar un proceso de selección de candidatos que incluya al menos una etapa de votación donde participen cinco mil personas o más (cifra ilustrativa) en la evaluación de cada candidato. Entre esas personas podría haber simpatizantes y no sólo militantes, según cuál sea el proceso de selección adoptado por el partido. En aquellos casos donde exista un pacto con otros partidos y se elija uno o más candidatos comunes, los participantes válidos para cumplir el requisito de cinco mil personas incluirían a militantes y simpatizantes de esos otros partidos.

Se define que un proceso de selección es una "primaria abierta" cuando incluye una etapa donde votan cinco mil personas o más. Se autoexcluyen de las ventajas propuestas aquellos partidos que inscriban candidatos que surjan de elecciones distritales donde participen sólo unos pocos cientos de personas.

- $\quad$ Para sujetar a las primarias abiertas a normas de control y transparencia del gasto electoral, el enfoque general propuesto es canalizar las primarias a través de los partidos políticos. Ellos ya están autorizados a recibir donaciones políticas y a gastar fuera de períodos de campaña. Este enfoque deja en manos de cada partido el sistema de votación y escrutinio, y aunque ello presenta algunas debilidades, tiene la ventaja de no cargar a los independientes con ese costo de una primaria ajena.

- $\quad$ Se propone otorgar las siguientes ventajas financieras permanentes a los partidos que adopten "primarias abiertas": 
- Acceso al sistema de donaciones de personas naturales por medios electrónicos que propone este informe, incluyendo el apoyo fiscal;

- Financiamiento público nuevo, consistente en un subsidio a las cuotas de militantes activos, definidos como aquellos que pagan cuotas regularmente y han votado en las elecciones internas ${ }^{4}$. El buen uso de este subsidio sería controlado por la Dirección de Fiscalización Electoral.

- Reducir los costos de transacción para las donaciones reservadas recibidas por los partidos e Institutos de Formación Política en períodos fuera de campaña oficial, bajando la periodicidad desde mensual a trimestral.

- $\quad$ Se proponen cargas adicionales para las "primarias abiertas" recién definidas: que las candidaturas (i) se sujeten a la definición de gasto electoral de la ley $\mathrm{N}^{\circ} 19.884$, (ii) lleven contabilidad, (iii) creen administradores electorales, (iv) tengan cuenta corriente única, (v) auditen dicha contabilidad con la Dirección de Fiscalización Electoral, (vi) cumplan las normas de transparencia de la contabilidad ante la ciudadanía, y se sujeten a la prohibición de recibir aportes de la administración del Estado.

- Muchos candidatos independientes a senador o diputado podrían resultar beneficiados con este esquema, pues no es posible aplicarles la carga de ganar elecciones internas. Para restaurar la igualdad de trato, conviene distinguir entre aquellos candidatos independientes que obtengan el patrocinio de más de cinco mil ciudadanos para inscribir su candidatura, de otros que obtengan menos. Se propone excluir a los independientes con más de cinco mil patrocinios de las últimas dos ventajas propuestas para los partidos, y excluir de las tres ventajas a los independientes con menos de cinco mil patrocinios.

En el caso de candidatos independientes a la presidencia, se propone autorizarlos a iniciar sus gastos de campaña a partir de la fecha de su inscripción como tal ante el Servicio Electoral, bajo la condición de que esta fecha sea posterior al inicio de una primaria abierta presidencial por parte de algún partido político. Esto permitirá que su campaña reciba aportes privados durante este período.

\footnotetext{
${ }^{4}$ Un ejemplo de tasas de subsidio donde el riesgo de fraude es pequeño: $30 \%$ de subsidio para cuotas trimestrales recibidas por un monto inferior o igual a 1 UTM por trimestre por militante activo, $15 \%$ para el exceso por sobre ese umbral hasta un segundo umbral de 7 UTM, y cero para el exceso.
} 


\section{ANEXO II}

\section{CONVENCIONES INTERNACIONALES CONSIDERADAS EN EL INFORME}

\section{Introducción}

Convención de las Naciones Unidas contra la Corrupción (Artículo 1. Finalidad)

“La finalidad de la Presente convención es:

a) Promover y fortalecer las medidas para prevenir y combatir más eficaz y eficientemente la corrupción;

b) Promover, facilitar y apoyar la cooperación internacional y la asistencia técnica en la prevención y lucha contra la corrupción, incluida la recuperación de activos;

c) Promover la integridad, la obligación de rendir cuentas y la debida gestión de los asuntos y bienes públicos”.

\section{Proposiciones en materia de transparencia activa y pasiva}

Convención de las Naciones Unidas contra la Corrupción (Artículo 10. Información Pública)

"Habida cuenta de la necesidad de combatir la corrupción, cada Estado Parte, de conformidad con los principios fundamentales de su derecho interno, adoptará las medidas que sean necesarias para aumentar la transparencia en su administración pública, incluso en lo relativo a su organización, funcionamiento y procesos de adopción de decisiones, cuando proceda. Esas medidas podrán incluir entre otras cosas:

a) La instauración de procedimientos y reglamentaciones que permitan al público en general obtener, cuando proceda, información sobre la organización, el funcionamiento y los procesos de adopción de decisiones de su administración pública y, con el debido respeto a la protección de la intimidad y de los datos personales, sobre las decisiones y actos jurídicos que incumban al público;

b) La simplificación de los procedimientos administrativos, cuando proceda, a fin de facilitar el acceso del público a las autoridades encargadas de la adopción de decisiones; y

c) La publicación de información, lo que podrá incluir informes periódicos sobre los riesgos de corrupción en su administración pública”. 
Convención de las Naciones Unidas contra la Corrupción (Artículo 13. Participación de la Sociedad)

Dentro de las medidas a través de las cuales debe reforzarse dicha participación considera: "b) Garantizar el acceso eficaz del público a la información”.

Convención de las Naciones Unidas contra la Corrupción (Artículo 6. Órgano u órganos de prevención de la corrupción)

"Cada Estado Parte, de conformidad con los principios fundamentales de su ordenamiento jurídico, garantizará la existencia de un órgano u órganos, según proceda, encargados de prevenir la corrupción”.

El mismo artículo dispone que se debe otorgar al órgano u órganos "la independencia necesaria de conformidad con los principios fundamentales de su ordenamiento jurídico, para que puedan desempeñar sus funciones de manera eficaz y sin ninguna influencia indebida. Deben proporcionárseles los recursos materiales y el personal especializado que sean necesarios, así como la capacitación que dicho personal pueda requerir para el desempeño de sus funciones”.

\section{Reformas al sistema de la alta dirección pública}

Convención Interamericana contra la Corrupción (Artículo 3 N 5)

Esta iniciativa responde a los requerimientos de la Convención Interamericana Contra la Corrupción, que señala que los Estados Partes deben considerar la aplicabilidad de medidas — dentro de sus propios sistemas institucionales - destinadas a crear, mantener y fortalecer: "Sistemas para la contratación de funcionarios públicos (...) que aseguren la publicidad, equidad y eficiencia”.

Convención de las Naciones Unidas contra la Corrupción (Artículo 7. Sector Público)

“1. Cada Estado Parte cuando sea apropiado y de conformidad con los principios fundamentales de su ordenamiento jurídico, procurará adoptar sistemas de convocatoria, contratación, retención, promoción y jubilación de empleados públicos y, cuando proceda, de otros funcionarios públicos no elegidos, o mantener y fortalecer dichos sistemas. Éstos: 
a) Estarán basados en principios de eficiencia y transparencia, y en criterios objetivos como el mérito, la equidad y la aptitud;

b) Incluirán procedimientos adecuados de selección y formación de titulares de cargos públicos que se consideren especialmente vulnerables a la corrupción, así como, cuando proceda, la rotación de esas personas a otros cargos;

c) Fomentarán una remuneración adecuada y escalas de sueldo equitativas, teniendo en cuenta el nivel de desarrollo económico del Estado Parte;

d) Promoverán programas de formación y capacitación que les permitan cumplir los requisitos de desempeño correcto, honorable, y debido de sus funciones y les proporcionen capacitación especializada y apropiada para que sean más conscientes de los riesgos de corrupción inherente al desempeño de sus funciones. Tales programas podrán hacer referencia a códigos o normas de conducta en las esferas pertinentes”.

Convención de las Naciones Unidas contra la Corrupción (Artículo 9. Contratación pública y gestión de la hacienda pública)

“1. Cada Estado Parte de conformidad con los principios fundamentales de su ordenamiento jurídico, adoptará las medidas necesarias para establecer sistemas apropiados de contratación pública, basados en la transparencia, la competencia y criterios objetivos de adopción de decisiones, que sean eficaces entre otras, para prevenir la corrupción. Estos sistemas en cuya aplicación se podrán tener en cuenta valores mínimos apropiados, deberán abordar entre otras:

a) La difusión pública de información relativa a procedimientos de contratación pública y contratos, incluida información sobre licitaciones e información pertinente u oportuna sobre la adjudicación de contratos, a fin de que los licitadores potenciales, dispongan de tiempo suficiente para preparar y presentar sus ofertas;

b) La formulación previa de las condiciones de participación, incluidos criterios de selección y adjudicación y reglas de licitación, así como su publicación;

c) La aplicación de criterios objetivos y predeterminados para la adopción de decisiones sobre contratación pública a fin de facilitar la ulterior aplicación correcta de las reglas o procedimientos;

d) Un mecanismo eficaz de examen interno, incluido un sistema eficaz de apelación para garantizar recursos y soluciones legales en el caso que no se respeten las reglas o los procedimientos establecidos conforme al presente párrafo; 
e) Cuando proceda, la adopción de medidas para reglamentar las cuestiones relativas al personal encargado de la contratación pública, en particular, declaraciones de intereses respecto de determinadas contrataciones públicas, procedimientos de selección y requisitos de capacitación”.

\section{El financiamiento de campañas y partidos políticos}

\section{Convención Interamericana contra la Corrupción (Artículo $2 N^{\circ}$ 1)}

Esta materia se encuadra con lo dispuesto por la Convención que indica que entre los propósitos que persigue está: "Promover y fortalecer el desarrollo, por cada uno de los Estados Partes, de los mecanismos necesarios para prevenir, detectar, sancionar y erradicar la corrupción”.

Convención de las Naciones Unidas contra la Corrupción (artículo 7. Sector Público)

“3. Cada Estado Parte considerará asimismo, la posibilidad de adoptar medidas legislativas y administrativas apropiadas, en consecuencia con los objetivos de la presente Convención y de conformidad con los principios fundamentales de su derecho interno, para aumentar la transparencia respecto de la financiación de candidaturas a cargos públicos electivos y, cuando proceda, respecto de la financiación de los partidos políticos”.

\section{Reforzamiento de los sistemas de control en el Estado}

Convención Interamericana contra la Corrupción (Artículo $3 N^{\circ}$ 9)

Los Estados Partes deben considerar la aplicabilidad de medidas destinadas a crear, mantener y fortalecer: "Órganos de control superior, con el fin de desarrollar mecanismos modernos para prevenir, detectar, sancionar y erradicar las prácticas corruptas”.

\section{Otras propuestas que favorecen la probidad}

Convención Interamericana contra la Corrupción (Artículo $3 N^{\circ} 8$ )

La convención demanda esta iniciativa al establecer el deber de que los Estados Partes cuenten con: "Sistemas para proteger a los funcionarios públicos y ciudadanos particulares que denuncien de buena fe, actos de 
corrupción, incluyendo la protección de su identidad, de conformidad con su Constitución y los principios fundamentales de su ordenamiento jurídico interno".

Convención de las Naciones Unidas contra la Corrupción (Artículo 8. Códigos de conducta para funcionarios públicos)

“4. Cada Estado Parte también considerará, de conformidad con los principios fundamentales de su derecho interno, la posibilidad de establecer medidas y sistemas para facilitar que los funcionarios públicos denuncien todo acto de corrupción a las autoridades competentes cuando tengan conocimiento de ellos en el ejercicio de sus funciones".

Convención Interamericana contra la Corrupción (Artículos 6, 2 y 33)

Conforme lo señala la convención, los Estados Partes deben considerar la aplicabilidad de medidas destinadas a crear, mantener y fortalecer: "Normas de conducta para el correcto, honorable y adecuado cumplimiento de las funciones públicas. Estas normas deben estar orientadas a prevenir conflictos de intereses y asegurar la preservación y el uso adecuado de los recursos asignados a los funcionarios públicos en el desempeño de sus funciones (...)” (artículo 2).

Protección de los denunciantes: Cada Estado Parte considerará la posibilidad de incorporar en su ordenamiento jurídico interno medidas apropiadas para proporcionar protección contra todo trato injustificado a las personas que denuncien ante las autoridades competentes, de buena fe y con motivos razonables, cualesquiera hechos relacionados con delitos tipificados con arreglo a la presente Convención (artículo 33).

Convención de las Naciones Unidas contra la Corrupción (Artículo 7. Sector Público)

“4. Cada Estado Parte, de conformidad con los principios fundamentales de su derecho interno, procurará adoptar sistemas destinados a promover la transparencia y a prevenir conflictos de intereses, o a mantener y fortalecer dichos sistemas".

Convención de las Naciones Unidas contra la Corrupción (Artículo 12. Sector Privado)

En el $N^{\circ} 2$ letra e) se consideran como medidas: "Prevenir los conflictos de intereses imponiendo restricciones apropiadas, durante un periodo 
razonable, a las actividades profesionales de ex funcionarios públicos o a la contratación de funcionarios públicos en el sector privado tras su renuncia o jubilación cuando esas actividades o esa contratación estén directamente relacionadas con las funciones desempeñadas o supervisadas por esos funcionarios públicos durante su permanencia en el cargo".

Convención de las Naciones Unidas contra la Corrupción (Artículo 8. Códigos de conducta para funcionarios públicos)

"1. Con objeto de combatir la corrupción cada Estado Parte, de conformidad con los principios fundamentales de su ordenamiento jurídico, promoverá, entre otras cosas, la integridad, honestidad y responsabilidad entre sus funcionarios públicos”.

Convención de las Naciones Unidas contra la Corrupción (Artículo 2. Definiciones)

Debe entenderse como funcionario público, conforme a esta disposición a "toda persona que ocupe un cargo legislativo, ejecutivo, administrativo o judicial de un Estado Parte, ya sea designado o elegido, permanente o temporal, (...)”.

Convención de las Naciones Unidas contra la Corrupción (Artículo 8. Códigos de conducta para funcionarios públicos)

“2. En particular, cada Estado Parte procurará aplicar, en sus propios ordenamientos institucionales y jurídicos, códigos o normas de conducta para el correcto, honorable y debido cumplimiento de las funciones públicas”.

Convención de las Naciones Unidas contra la Corrupción (Artículo 13. Participación de la sociedad)

Conforme al artículo 13 № 1 letra a) de la convención la participación de la sociedad deberá reforzarse con medidas como "aumentar la transparencia y promover la contribución de la ciudadanía a los procesos de adopción de decisiones” entre otras. 